ScIDoC

\section{International Journal of Dentistry and Oral Science (IJDOS) ISSN: 2377-8075}

\title{
Lasers and their Applications in the Dental Practice
}

\author{
Research Article
}

Anitha Krishnan Pandarathodiyil ${ }^{1}$, Sukumaran Anil $1^{2,3^{*}}$

${ }^{1}$ Department of Oral Diagnostic Sciences, Faculty of Dentistry, SEGi University, Selangor, Malaysia.

${ }^{2}$ Department of Dentistry, Oral Health Institute, Hamad Medical Corporation, Doha, Qatar.

${ }^{3}$ College of Dental Medicine, Qatar university, Doha, Qatar.

\section{Abstract}

The objective of implementing newer techniques in dentistry is to overcome the shortcomings of traditional ones. Dentistry, being a dynamic field, is always on the lookout for innovative techniques, and embracing newer technology has indeed improved patient care in many ways. Lasersare being used as an adjunct or alternative tool to conventional dental procedures. Many dental disciplines such as oral surgery, oral medicine, periodontics, paediatric dentistry, implantology, and operative dentistry have benefitted from the use of laser technology. Lasers have become an invaluable tool in many procedures, including caries removal, caries decontamination, caries prevention, cavity preparation, soft tissue surgeries, root canal decontamination, analgesic and anti-inflammatory effects, to name a few. Laser treatment in dentistry can be quicker and more efficient. Other benefits would include markedly less pain, lack of bleeding, minimal need of anaesthesia and reduced postoperative discomfort. Also, patients may be able to resume their daily activities shortly after the treatment is rendered, owing to faster healing. However, the caveat would be that adequate training is a mandatory prerequisite before handling patients with these powerful instruments. This article briefly reviews the basic science of lasers and gives a brief account on the updates of their diverse applications in the general dental practice.

Keywords: Lasers; Dentistry; Adjunctive Techniques; Laser Physics; Clinical Applications.

\section{Introduction}

LASER is an acronym for 'Light Amplification by the Stimulated Emission of Radiation' and was introduced by Gordon Gould [1]. As the acronym goes, laser is a device that generates light through a process of optical amplification based on the stimulated emission of electromagnetic radiation [2]. Historically, dental lasers were first introduced by Ralph H. Stern and Reidar Sognnaes, who used a ruby laser to vaporize enamel and dentin. Although they were successful in the ablation of the hard tissues, the procedure caused an unhealthy increase in temperature, which injured the pulp [3]. Because of this undesirable collateral damage, usage of dental lasers was put on hold for over two decades until the successful application of the Neodymium Yttrium Aluminium Garnet (Nd:YAG) lasers by Terry Myers in 1989. This was further approved by the FDA (food and drug administration), USA [4] and from then on, over the last three decades, lasers have been used in various aspects of dentistry, with immense success and advancements.
Dentistry, being a dynamic field, is always on the lookout for innovative and advanced materials and techniques and embracing such innovative technology has improved patient care in many ways. The objective of implementing newer techniques and materials in dentistry is to overcome the shortcomings of traditional ones. Lasers are being used as an adjunct or alternative instrument to conventional dental procedures. Many dental disciplines such as oral surgery, oral medicine, periodontics, paediatric dentistry, implantology, and operative dentistry have benefitted from the use of laser technology. Lasers have become an invaluable tool in many procedures, including caries removal [5], caries decontamination [6], caries prevention [7], cavity preparation [8], soft tissue surgery [9], root canal decontamination [10] and anti-inflammatory effects [11]. Laser treatment in dentistry can be quicker and more efficient. Other benefits would include markedly less pain, lack of bleeding, nominal need of anaesthesia, and minimal postoperative discomfort. Also, patients may be able to resume their daily activities shortly after the treatment is rendered, owing

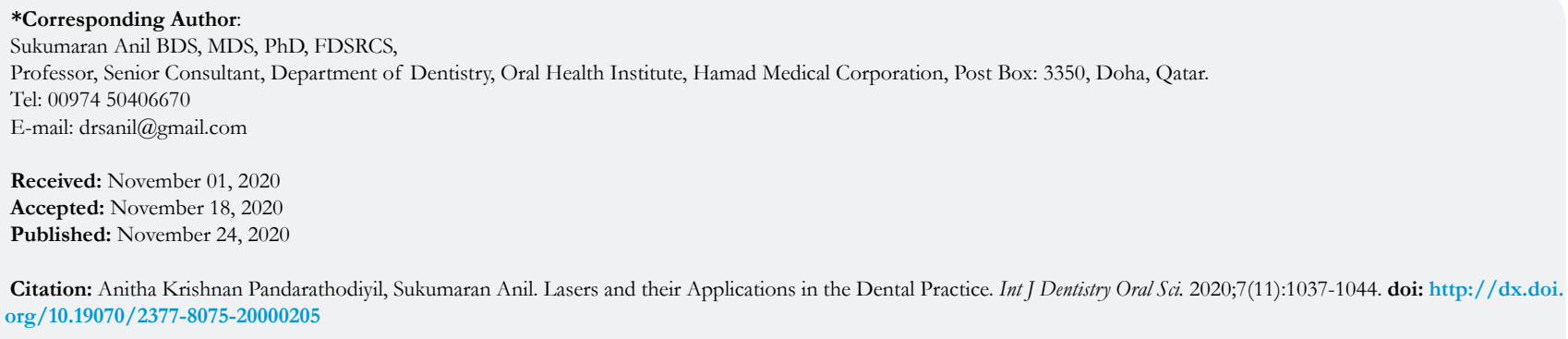

Copyright: Sukumaran Anil ${ }^{\odot} 2020$. This is an open-access article distributed under the terms of the Creative Commons Attribution License, which permits unrestricted use, distribution and reproduction in any medium, provided the original author and source are credited. 
to faster healing. This article briefly reviews the basic science of lasers and gives a brief account on the updates of their diverse applications in general dental practice.

\section{Laser Physics}

In laser technology, a laser beam is created from a substance known as an active medium. When the active medium is stimulated by light or electricity it produces photons of a specific wavelength. This laser light has coherent, polarized, and monochromatic electromagnetic waves within a narrow frequency range [12]. Laser light is called monochromatic because the beam is made of a single wavelength of light. Unlike ordinary light, laser light travels in one direction (unidirectional). Coherence is the property that allows the light beam to travel in a single wavelength with the peaks and valleys in unison. The degree of penetration of the laser light into the tissues is determined by the wavelength of the light used [13]. In dentistry, the available commercial dental lasers are in the range of $377 \mathrm{~nm}$ to $10,600 \mathrm{~nm}$ and are all nonionizing electromagnetic radiation without causing any mutations to the cellular DNA components like gamma-rays and X-rays [14]. The emission wavelengths are either within the visible or invisible infra-red, non-ionizing portion of the electromagnetic spectrum. Hence they emit either a visible wavelength of light or an invisible infrared or UV light [15]. Energy absorbed during laser therapy is dependent on the wavelength and characteristics of the tissue such as pigmentation, water content, etc. The principal interaction between tissue and the laser light is photothermic, in which the laser energy is converted to heat energy. In clinical settings, this heat energy can be directed to be used for three different effects such as incision or excision, ablation or vaporization and haemostasis or coagulation [16-18].

A laser unit consists of a laser medium placed within an optical resonant cavity. It is connected to a power supply and a cooling system that can be controlled. The resonant optical cavity in which the lasing medium is placed, houses two mirrors placed away from each other at some distance and aligned in such a way that their reflecting surfaces face each other (Figure 1) [15]. Photons bounce back and forth off the mirrors and re-enter the medium to stimulate the release of more photons, and thus generating light. This high-intensity light will bounce back and forth many times across the laser medium increasing in power with each bounce. A partially reflective mirror is placed within the cavity which reflects about $80 \%$ of the incident light while $20 \%$ of the light leaks back into the cavity. This leaked light is the monochromatic, and unidirectional beam of laser light. Laser light gets converted from the power pumped into the laser medium. Some of the input power is converted into heat, raising the temperature of the laser medium. Any light energy that does not pass perpendicularly between the two reflective mirrors will go astray and be lost as heat which has to be removed from the resonant cavity. This is done by a cooling system, which maintains the temperature of the laser medium at an optimal level, consistent with the maximum lasing efficiency. Laser power and other parameters are also controlled by a microchip/microprocessor placed within the unit [15].

\section{Laser Tissue Interactions}

When laser light comes in contact with oral tissues, one or more of these four possible interactions can occur such as absorption, reflection, transmission, or scattering (Figure 2) [19]. Animal cells

Figure 1. Schematic Representation of the Components of a Laser Unit.

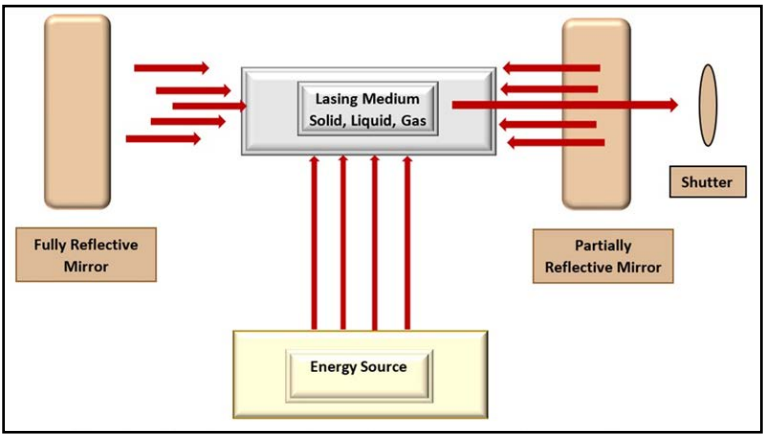

Figure 2. Schematic Representation of Laser-Tissue Interactions.

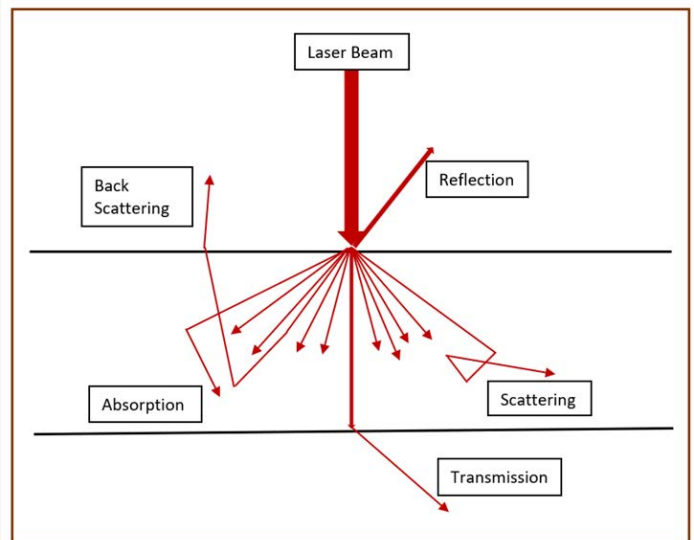


contain water molecules and specific photon absorbing molecules called chromophores, which absorb light energy. When laser light penetrates a tissue site, absorption of the photons by the chromatophores and water takes place. The absorbed light energy then gets converted to another form of energy like thermal and/ or mechanical energy. Absorption is the most vital interaction among all the laser-tissue interactions, in which transference of energy to the tissue takes place, and the desired clinical effect is exerted. It is also important to note that the absorption characteristics of the photonic emission by a particular wavelength of a laser light are different for the same tissues. The amount of absorption of the laser light is directly proportional to the water content of the tissue, which means that absorption is more in tissues with higher water content. During reflection, there is no penetration or absorption of the laser beam. Instead the light bounces off the tissue surface. During the tissue interaction of transmission, the laser beam penetrates through the superficial layers to interact with the deeper tissues and is unchanged. Scattering is the phenomenon wherein the laser beam gets scattered in many directions after penetrating the tissue, without producing a noticeable effect within the tissue. Among the four tissue interaction phenomena, the least useful are reflection and scattering, with absorption being the most important. In the wavelength range of $600-1600 \mathrm{~nm}$, there is more scattering when compared to absorption, and penetration to a depth of $8-10 \mathrm{~mm}$ would occur. At the same time, due to backscattering, the intensity of the reflected light would increase to about $35-70 \%$ of the total incident light [20].

\section{Biological Effects of Laser light}

Apart from the four laser-tissue interactions, there are biological effects that occur once the light has interacted with the tissues. They are photochemical reactions (such as tissue fluorescence, photodynamic effects, photomodulation or biomodulation) photothermal effects, photodisruptive or photoacoustic effects, and photoplasmolysis $[15,20]$.

\section{Photochemical Reactions}

When naturally occurring, chromophores absorb certain wavelengths of laser light certain biochemical reactions take place at the cellular level. These effects are seen due chemical energy caused by photons within tissues, and include tissue fluorescence, photomodulation or biomodulation, and photodynamic effects $[15,20]$.

\section{Tissue Fluorescence}

It is the property of some atoms and molecules to absorb light at a particular wavelength and subsequently emit light of a longer wavelength after a brief interval of time. This property in laser therapy is useful in hard tissue management. When a tooth with an active carious lesion is exposed to a suitable laser beam (655 $\mathrm{nm}$ ), fluorescence can be seen. The amount of fluorescence is dependent on the size of the lesion, and is therefore useful in diagnosing and managing early carious lesions [13].

\section{Photomodulation or Biostimulation}

This is also known as low level laser therapy. When appropriate wavelengths of laser light are used, photomodulation or biomodulation can hasten the healing process of injuries, increase blood flow, and reduce pain and swelling, through biological processes such as increased collagen and bone synthesis, fibroblast proliferation, enhanced efficacy of leucocyte phagocytosis, etc. In dentistry, biostimulation is used mostly for post-operative healing and ulcerations like recurrent herpes and aphthous. Usually, the laser light is used in non-contact mode while performing biostimulation $[21,22]$.

\section{Photodynamic Effects}

Under light excitation, reactive oxygen species can be generated which cause cellular toxicity and other biological effects. Photodynamic effect is employed in photodynamic therapy and disinfection wherein the reactive oxygen species are generated following laser excitation to produce the desired biological effect [22].

\section{Photothermal Effect}

The property of absorbing laser energy and transforming it to heat energy is photothermal effect. This heat energy is then used to perform work on soft tissues in the form of placing incision, initiating coagulation, ablation and photopyrolysis. In hard tissues, photothermal effects can be used to vaporize enamel and dentin. However, due to the excessive heat produced utmost care must be taken to prevent tissue injuries $[15,20]$.

\section{Photodisruptive Effects}

This property is also known as photo-acoustic effect. When high powered, pulsed, and short bursts of laser light is made to interact with tissue, the water molecules within the tissue undergo rapid thermal expansion. This in turn causes thermo-mechanical acoustic shock waves that can cause ablation and disrupt hard tissues. The high ablation efficiency of certain lasers such as Erbium lasers is derived from the micro-explosion of the superheated water molecules within the tissues that have absorbed the laser energy. However, the resultant effect causes pulverization of the tissues through the photomechanical ablation, rather than vaporization. Thus, the shock waves do not cause any thermal damage as there is almost no residual heat created [20].

\section{Photoplasmolysis}

When energy from the laser light is absorbed by tissue, electrically charged ions exist in a "plasma" state which is a semi-gaseous, high energy state and is not solid, liquid or gas. This plasma state is maintained by the absorption of the laser energy and through electron vibrations causes rapid expansion and contraction producing disruptive shock waves that break apart target materials. In this process, tissue removal is facilitated through the formation of the 'plasma' state ions and molecules [15].

\section{Types of Dental Lasers}

Dental lasers may be categorized into three basic groups such as soft tissue lasers, hard tissue lasers, and non-surgical devices like diagnostic/composite and photodisinfectionlasers (Flowchart 1) [23]. There are also four classes of lasers based on the potential danger posed to the eyes as a result of their inherent power. 
CD players belong to class 1 lasers while class 2 include the laser pointers. Low level lasers used in low level laser therapy (LLLT) belong to class 3 lasers along with CD and DVD writers. Class 4 includes the surgical lasers [2]. Most lasers used in dentistry are considered class 4 lasers. These lasers require eye protection in the form of safety glasses for the patient, the clinician, and the assisting staff [24]. There are many methods of classifying lasers. They can be classified according to the active element used within them, that goes through the stimulated quantum transitions, and creates the light. This could be gas (eg. Carbon dioxide lasers), liquid (eg. Organic dye laser), solid (eg. Ne: YAG) or semiconductor diode (eg. hybrid silicon laser). Dental lasers routinely used in dentistry are summarized in table 1 [25].

The wavelength and frequency of the laser light are another way of classifying dental lasers. However, these parameters of the light are dependent on the active element within the laser [26]. They can also be classified based on the type of tissues they are used on, such as hard tissue lasers (hard lasers) and soft tissue lasers (soft lasers). Hard lasers are also termed as hot lasers while soft lasers are known as cold lasers. Lasers that are within the visible spectrum of light are the Alexandrite laser with $377 \mathrm{~nm}$, the blue diode laser at 445nm, argon laser at 488nm and 514nm, KTP (Potassium Titanyl Phosphate) laser at 532nm, and $\mathrm{He}-\mathrm{Ne}$ (Helium Neon) at $632 \mathrm{~nm}$. The rest of the laser systems used in dentistry fall under the invisible, infra-red portion of the electromagnetic spectrum. Examples would include the diode laser (805, 808, 810, 830, 940, 980 and 1064nm), Nd:YAG laser (1064nm), the Erbium family lasers with the Er,Cr:YSGG laser $(2780 \mathrm{~nm})$ and Er:YAG laser $(2940 \mathrm{~nm})$, the $\mathrm{CO}_{2}$ laser $(9300,9600 \& 10600 \mathrm{~nm})$ [27]. All dental lasers are capable of being absorbed by one or more components of the soft tissues. The lasers that are under the infrared umbrella are divided into two main categories: viz., the short wavelength lasers in the near-infrared spectrum (800$1100 \mathrm{~nm})$ and the longer wavelength lasers in the mid and far infrared spectrum.

The short wavelength lasers are ideal for soft tissue procedures because of their tendency for minimal or no interaction with the dental hard tissues They are selectively absorbed by the vascular components and tissue pigments in areas of inflammation [28]. They have a low absorption coefficient in water with scattering into healthy soft tissues to about 0.8-6.0 $\mathrm{mm}[29]$. These lasers are ideal for soft tissue procedures such as frenectomy, operculecto-

Flowchart 1. Types od Dental lasers and their Applications.

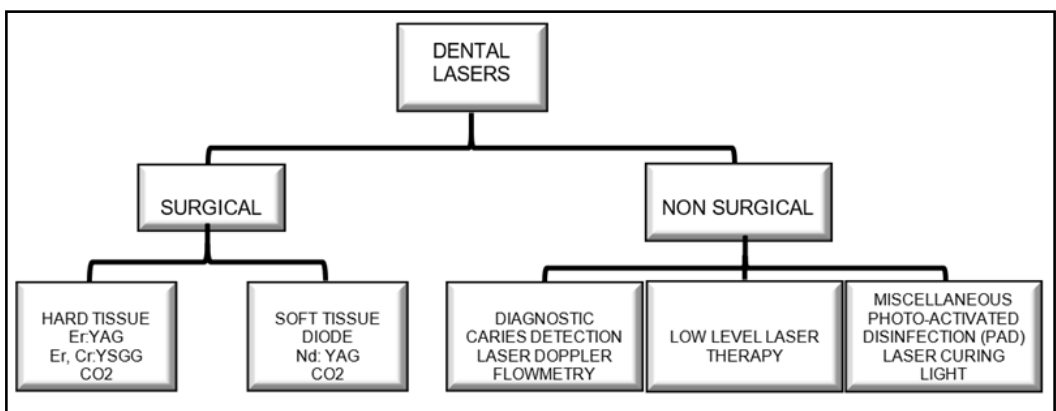

Table 1. Types of routinely used dental lasers and their applications.

\begin{tabular}{|c|c|c|c|c|}
\hline Construction & Laser type & $\begin{array}{l}\text { Wavelength } \\
\text { (nm) }\end{array}$ & Delivery system & Applications \\
\hline Gas laser & Argon & 488,515 & Optical fibre & $\begin{array}{l}\text { soft-tissue incision and ablation, } \\
\text { curing resins, bleaching }\end{array}$ \\
\hline Gas laser & Carbon dioxide $\mathrm{CO}_{2}$ & 966,10600 & $\begin{array}{l}\text { Waveguide, articu- } \\
\text { lated arm }\end{array}$ & $\begin{array}{l}\text { de-epithelialization of gingiva } \\
\text { during periodontal regenerative } \\
\text { procedures }\end{array}$ \\
\hline Gas laser & Helium-Neon & 633 & Optical fibre & $\begin{array}{l}\text { caries detection, diagnosis, wound } \\
\text { healing, pain reduction }\end{array}$ \\
\hline Solid state & $\begin{array}{l}\text { Potassium-Titanyl- } \\
\text { Phosphate (KTP) }\end{array}$ & 532 & Optical fibre & photochemical bleaching \\
\hline Solid state & Nd:YAG & 1064 & Optical fibre & $\begin{array}{l}\text { soft-tissue incision and ablation; } \\
\text { incipient caries removal }\end{array}$ \\
\hline \multirow{2}{*}{ Solid state } & \multirow{2}{*}{ Er:YAG } & \multirow{2}{*}{2940} & \multirow{2}{*}{$\begin{array}{l}\text { Optical fibre, Wave- } \\
\text { guide, articulated arm }\end{array}$} & $\begin{array}{l}\text { caries removal, cavity preparation } \\
\text { in }\end{array}$ \\
\hline & & & & $\begin{array}{c}\text { enamel and dentin, root canal } \\
\text { preparation }\end{array}$ \\
\hline \multirow[t]{2}{*}{ Solid state } & \multirow[t]{2}{*}{ Er,Cr:YSGG } & \multirow[t]{2}{*}{2780} & \multirow[t]{2}{*}{ Optical fibre } & $\begin{array}{l}\text { enamel etching, caries removal, } \\
\text { cavity preparation, }\end{array}$ \\
\hline & & & & root canal preparation \\
\hline Semiconductor & Diode & $\begin{array}{c}635,670,810 \\
830,980\end{array}$ & Optical fibre & Soft-tissue incision and ablation \\
\hline
\end{tabular}


my, gingivectomy, gingival troughing, periodontal pocket debridement, second stage implant uncovering, fibroma removal, and oral biopsy etc [30]. They are also used in direct laser irradiation in conventional laser endodontic therapy, tooth bleaching, and dentin desensitization. The longer wavelength lasers exhibit high absorption coefficient of water. This makes them selective for soft tissue procedures due to the presence of high-water content in the oral mucosal tissues. When soft tissue ablation is performed through vaporisation of the interstitial tissue fluid, fragmentation of tissue structure is noted, achieving both hard and soft tissue laser applications at the same time. The lasers under this category, Er, Cr:YSGG, Er:YAG and $\mathrm{CO}_{2}$ lasers, are efficient in the removal of calculus through scaling $\&$ root planning the periodontal pocket, indirect laser irradiation, and photoacoustic effect in endodontic procedures. They are also useful in the treatment of inflammatory conditions such as mucositis \& periimplantitis, as well as bone cutting and restorative procedures [21].

\section{Clinical Applications}

In health sciences, the most commonly used lasers involve thermal interaction in which heat is generated following irradiation, which gets converted into controlled temperature rises in small and specific areas of the target tissues [31]. Microstructural and physical changes in target tissues occur depending on the rise in temperature and the laser-tissue interactions. If the lasers used are of high-power category the effects such as vaporisation, coagulation, and ablation can occur.

\section{Disinfection}

The property of photodynamic effects of the laser light on tissues is employed in disinfection. There are certain types of dyes that can release oxygen species when activated by laser light. They are called as photoactivated dyes (PAD). The singlet oxygen species released by these dyes can be bactericidal because of their damaging effects exerted on the bacterial membranes and DNA. This property of PAD can be utilized in disinfection of periodontal pockets [32], root canals [33], deep carious lesions [34] and periimplantitis [35]. The PAD technique utilises a range of visible red and near infrared lasers, and systems using low power visible red semiconductor diode lasers, and toluidine blue dye. It is effective in killing bacteria in sub-gingival plaque which are resistant to the action of antimicrobial agents [36]. As visible red light travels well across dentinal tissue, detection of deep carious lesions can be made with this property [37]. Photo activated dye therapy does not possess any deleterious thermal effects on the surrounding tissues or the cellular components of the oral mucosa such as fibroblasts or keratinocytes [38]. Neither toluidine blue nor the oxygen species is injurious to the patients. The residual reactive oxygen species are cleared by catalase, an enzyme which is always present in tissues and peripheral circulation [39].

\section{Detection and Diagnosis}

Low power laser energy has been used in diagnosis, both in clinical settings and dental research. Low power lasers operate at powers of 100 milliwatts or less and produce energy in the visible spectrum (400-700nm wavelength), or in the ultraviolet (200$400 \mathrm{~nm})$, or near infrared regions (700-1500nm) [24]. Diagnosis of caries and periodontal disease can be achieved by a phenomenon known as laser-induced fluorescence. Conventional probing of enamel with dental probe is discouraged as it can further destroy the enamel surface and cause cavitation. Photons of $655 \mathrm{~nm}$ is emitted at the target tooth surface whereby the bacteria present within the carious tooth surface or calculus-laden root surface will display fluorescence. When the laser light irradiates the tooth, it is absorbed by the organic and inorganic components of the dental tissues, as well as by metabolites such as bacterial porphyrins. These porphyrins show fluorescence after excitation by red light. The presence of bacteria in the carious lesions, causes the carious tissue to exhibit more fluorescence when compared to the healthy tooth [40]. The laser system usually has a display unit which shows the number of bacteria present at a particular area of the tooth. The amount of fluorescence and the number of bacteria displayed in the unit would provide a fair idea of the presence of caries or periodontal disease. It can detect interproximal, occlusal, and occult carious lesions beneath fissure sealants [41]. However, this is recommended to be used as an adjunctive tool, and patient's clinical examination and radiographs are gold standards for diagnosing dental caries and periodontal disease [42].

\section{Analgesia, Inflammation and Tissue Repair}

Low level laser therapy (LLLT), typically with a wavelength of about $660 \mathrm{~nm}$ to $905 \mathrm{~nm}$ in the red to near infrared region of the spectrum, are capable of penetrating the skin and soft/hard tissues, and enable photo-biostimulation, and as a result have been successful in relieving pain, reducing inflammation, and enhancing tissue repair. The irradiance is usually between $5 \mathrm{~W} / \mathrm{cm}^{2}$ and is applied to an injury or a painful site for 30-60 seconds, a few times a week, for several weeks. This results in reduction of inflammation, relief of pain, and acceleration of tissue regeneration [2]. In the dental office, pain alleviation for conditions such as aphthous ulcers and post herpetic neuralgia with LLLT have been successfully performed $[43,44]$. When LLLT is administered at the early tingling phase, photostimulation blocks the lesions before painful vesicles are produced, accelerates the healing time, and reduces the recurrence of lesion [45]. Pain following tooth movement during orthodontic treatment has been alleviated with the use of LLLT. LLLT has also been helpful in the acceleration of orthodontic tooth movement without adverse effects [46]. Pain produced by dentine hypersensitivity can vary from mild to severe. LLLT has been implemented in the relief of severe dentine hypersensitivity successfully with rapid results in short duration of time when compared to desensitizing medications [47]. Postoperative pain, inflammation, and trismus following third molar surgery respond well to LLLT and have resulted in the reduction in these symptoms rapidly [48]. Neuropathic pain conditions such as post herpetic neuralgia [49], trigeminal neuralgia [50] can also be treated with LLLT with clinical success.

\section{Photodynamic Therapy}

Photodynamic therapy (PDT) is a laser-initiated photochemical reaction. It is also known as photo-radiotherapy, phototherapy, or photo-chemotherapy. PDT employs the use of a photoactive dye, known as photosensitizer, that is activated by the exposure to laser light of a specific wavelength in the presence of oxygen. This results in the formation of toxic oxygen species such as singlet oxygen and free radicals. These oxygen species are toxic to cellular components such as proteins, lipids, nucleic acids, among others 
[51]. PDT has various applications in the dental practice including treatment of oral cancer, oral microbial infections, and diagnosis of malignant transformation of oral lesions. PDT uses the combination of the non-toxic photosensitizer and a harmless light to generate reactive oxygen species that kills tumours cells by direct tumor cell destruction, vascular shutdown, and activation of the host immune system [52]. PDT triggers a mixture of apoptotic and necrotic cell death which is different from most conventional cytotoxic agents that usually only trigger apoptotic cell death [53]. Oral leucoplakia's with moderate to severe dysplasia, and oral lichen planus have seen complete remissions and decreased inflammation respectively, following treatment with PDT [54, 55]. Photodynamic antimicrobial chemotherapy (PACT) has been effective in the treatment of microbial infections like oral bacterial, fungal, parasitic, and viral infections. Since PDT does not pose any genotoxic or mutagenic effects, its long-term safety during treatment is not a concern. PDT also provides a therapeutic approach in the management of oral biofilms by disruption of the plaque structure which is vital for homeostasis of biofilms [56].

\section{Caries, Calculus Removal and Cavity Preparation}

In restorative dentistry, lasers have been successfully implemented for cavity preparation [8], caries prevention [7], caries decontamination [6] and caries removal [5]. For these procedures, high intensity lasers, which promote controlled temperature rise in a small and specific area of dental hard tissues, are needed [31]. The use of lasers for cavity preparation and caries removal is based on the ablation mechanism which is also known as explosive (water-mediated) tissue removal, in which dental hard tissue are removed by thermal and/or mechanical effect during laser irradiation. This mechanism relies on the type of tissue to be irradiated, as well as the characteristics of laser equipment. Ablation occurs as a result of fast heating of the subsurface water present in dental hard tissue matrix, and due to the higher interaction with infrared laser irradiation. The heating of these water molecules leads to an increase in molecular vibration and, consequently, an increase in subsurface pressures that can exceed the strength of the target tissue. The tissue removal is seen at temperatures of melting point of dental hard tissues and varies according to the laser wavelength. The most effective lasers used for caries removal and cavity preparations are the Er: YAG and Er, Cr, YSGG [57]. Based on the same principle, the Er: YAG lasers are also used for calculus removal and as the bacterial porphyrins in dental calculus emit strong fluorescence signals, these can be used to control lasers for scaling. However, since the Er: YAG laser is capable of ablating tooth substance, removal of enamel calculus is contraindicated. Calculus of the subgingival root surface, or exposed root surface due to gingival recession, or root surface exposed during periodontal surgery are ideal candidates for removal by laser [58]. Conventional mechanical treatment of periodontally diseased root surfaces within the periodontal pocket may have limitations such as accessibility and bactericidal effect. Lasers have been found to be effective in removing lipopolysaccharides and root surface endotoxins and are highly bactericidal against periodontopathogens including P. gingivalis and Actinobacillus actinomycetemcomitans [59].

\section{Soft Tissue Procedures}

There are numerous soft tissue procedures which can be per- formed with lasers. The vital features of the procedures are control of bleeding intra-operatively, and reduction in post-operative pain compared to conventional techniques such as scalpel or electrosurgery. The degree of absorption in target tissue components determines the type of effect gained by the laser on soft tissues, and hence, water and haemoglobin content in oral tissues becomes important for the efficient absorption of many commonly used dental lasers. Certain procedures in patients with bleeding disorders are ideal for lasers with greater haemostatic capabilities [25]. Lasers are widely used in gingival and periodontal surgeries, coagulation and haemostasis procedures, incisional and excisional biopsies of soft tissue lesions, TMJ disorders, exposure of implants, pre-prosthetic surgery, etc. In periodontics, laser is a viable tool for procedures such as frenectomy, gingivectomy and genioplasty, gingival re-sculpting, de-epithelization of reflected periodontal flaps, removal of granulation tissue and crown lengthening [60]. Incisional and excisional intraoral biopsies can be performed using lasers of all dental wavelengths. Due to minimal discomfort and trauma with excellent hemostasias, postoperative sutures are minimally used if any [61]. The diode lasers with their wavelength between $810 \mathrm{~nm}$ to $980 \mathrm{~nm}$, are useful in the treatment of soft tissue lesions. These have been used successfully for facial depigmentation, excision of soft tissue lesions such as fibroma, pyogenic granuloma etc., and vascular lesions [62].

\section{Control of Gag Reflex}

It is a well-known fact that acupuncture is commonly used to help relieve symptoms such as nausea and vomiting, among others. Gag reflex is a significant deterrent to many procedures such as placement of $\mathrm{x}$-ray films, tongue retraction, impression taking, etc., especially in children. The acupuncture points related to nausea is known as Nei Guan or P6 points. These points are located three finger breadths below the wrist on the inner forearm. Low level laser stimulation of the PC 6 acupuncture points with 4J/ $\mathrm{cm}$, just before the procedure, appears to be a useful technique for controlling gag reflex in children [63]. Stimulation of these points by low level laser energy was also seen to alleviate anxiety, improve oxygen saturation as well as attenuate gag reflex in children [64].

\section{Nerve Repair and Regeneration}

It has been found that in patients with long-term peripheral nerve injury laser therapy with 780-nm laser phototherapy can progressively improve nerve function, leading to significant functional recovery of peripheral nerves [65]. In dentistry, although rare, the most severe complication after the removal of mandibular wisdom teeth is injury to the inferior alveolar nerve or the lingual nerve. Most of the times, these injuries are transient and reversible. However, in some cases, the damage could be chronic causing long-term disability. Low level laser therapy has been found with some success in reducing the chronic sensory nerve impairment following third molar removal [66]. Another study investigated the therapeutic effects of $660 \mathrm{~nm}$ and $880 \mathrm{~nm}$ photobiomodulation therapy following inferior alveolar nerve crush injury in Wistar rats. The results suggested that photobiomodulation therapy with the $808 \mathrm{~nm}$ wavelength enhanced inferior alveolar nerve regeneration after nerve crush injury [67]. 


\section{Conclusion}

Laser technology in dentistry has advanced leaps and bounds since its inception in the 1960's. It offers many useful clinical applications for general dentists and specialists in the diagnosis and treatment of patients. The caveat is to properly train clinicians to use this technology safely and prudently. Laser procedures must be performed by those with adequately acquired skill, and complete understanding of the effects and limitations of this advanced instrument. In the right hands, it can be a very powerful adjunctive tool which can help to overcome the setbacks of conventional techniques.

\section{References}

[1]. Gross AJ, Herrmann TR. History of lasers. World J Urol. 2007 Jun $1 ; 25(3): 217-20$.

[2]. Cotler HB, Chow RT, Hamblin MR, Carroll J. The use of low level laser therapy (LLLT) for musculoskeletal pain. MOJ Orthop Rheumatol. 2015;2(5).

[3]. STERN RH, SOGNNAES RF. LASER EFFECT ON DENTAL HARD TISSUES. A PRELIMINARY REPORT. J South Calif State Dent Assoc. 1965 Jan;33(1):17-9.Pubmed PMID: 14241171.

[4]. Myers TD, Myers WD, Stone RM. First soft tissue study utilizing a pulsed Nd:YAG dental laser. Northwest Dent. 1989 Mar-Apr;68(2):14-7.Pubmed PMID: 2622793.

[5]. Neves Ade A, Coutinho E, De Munck J, Van Meerbeek B. Caries-removal effectiveness and minimal-invasiveness potential of caries-excavation techniques: a micro-CT investigation. J Dent. 2011 Feb;39(2):154-62.Pubmed PMID: 21111770.

[6]. Nammour S, Zeinoun T, Bogaerts I, Lamy M, Geerts SO, Bou Saba S, et al. Evaluation of dental pulp temperature rise during photo-activated decontamination (PAD) of caries: an in vitro study. Lasers Med Sci. 2010 Sep;25(5):651-4.Pubmed PMID: 19488675

[7]. Zezell D M,Boari H G,Ana P A, Eduardo Cde, P; Powell, G L. Nd:YAG laser in caries prevention: a clinical trial. Lasers Surg Med. 2009;41:31-35.

[8]. De Moor RJ, Delme KI. Laser-assisted cavity preparation and adhesion to erbium-lased tooth structure: part 2. present-day adhesion to erbium-lased tooth structure in permanent teeth. J Adhes Dent. 2010 Apr;12(2):91-102. Pubmed PMID: 20157678

[9]. De Moor RJ, Delme KI. Laser-assisted cavity preparation and adhesion to erbium-lased tooth structure: part 2. present-day adhesion to erbium-lased tooth structure in permanent teeth. J Adhes Dent. 2010 Apr;12(2):91-102. Pubmed PMID: 20157678

[10]. Benedicenti S, Cassanelli C, Signore A, Ravera G, Angiero F. Decontamination of root canals with the gallium-aluminum-arsenide laser: an in vitro study. Photomed Laser Surg. 2008 Aug;26(4):367-70.Pubmed PMID: 18637718.

[11]. Lang-Bicudo L, Eduardo Fde P, Eduardo Cde P, Zezell DM. LED phototherapy to prevent mucositis: a case report. Photomed Laser Surg. 2008 Dec;26(6):609-13.Pubmed PMID: 19025412.

[12]. Goldman L, editor. The biomedical laser: technology and clinical applications. Springer Science \& Business Media; 2013 Nov 9.

[13]. Dederich DN. Laser/tissue interaction: what happens to laser light when it strikes tissue? J Am Dent Assoc. 1993 Feb;124(2):57-61.Pubmed PMID: 8429185 .

[14]. Musale PK, Soni AS, Mujawar S, Musani I. Use of Nd: YAG laser in the treatment of ankyloglossia for pediatric patient. J. Dent. Lasers. 2012 Jan $1 ; 6(1): 33$

[15]. Sulieman M. An overview of the use of lasers in general dental practice: 1 . Laser physics and tissue interactions. Dent Update. 2005 May;32(4):22830, 233-4, 236.Pubmed PMID: 15938343.

[16]. Romanos GE. Diode laser soft-tissue surgery: advancements aimed at consistent cutting, improved clinical outcomes. Compend Contin Educ Dent. 2013 Nov-Dec;34(10):752-7; quiz 758.Pubmed PMID: 24571504.

[17]. Behdin S, Monje A, Lin GH, Edwards B, Othman A, Wang HL. Effectiveness of laser application for periodontal surgical therapy: systematic review and meta-analysis. J Periodontol. 2015 Dec;86(12):1352-63.

[18]. Marín-Conde F, Castellanos-Cosano L, Pachón-Ibañez J, Serrera-Figallo MA, Gutiérrez-Pérez JL, Torres-Lagares D. Photobiomodulation with lowlevel laser therapy reduces oral mucositis caused by head and neck radiochemotherapy: prospective randomized controlled trial. Int J Oral Maxillofac Surg. 2019 Jul;48(7):917-923.Pubmed PMID: 30591391.
[19]. Zezell DM, Ana PA. High power lasers and their interaction with biological tissues. Lasers in Dentistry: Guide for Clinical Practice. 2015 Feb 17;33:11.

[20]. Douplik A, Saiko G, Schelkanova I, Tuchin VV. The response of tissue to laser light. InLasers for Medical Applications 2013 Jan 1 (pp. 47-109). Woodhead Publishing.

[21]. Convissar RA. Principles and Practice of Laser Dentistry-E-Book. Elsevier Health Sciences; 2015 Mar 6.

[22]. Manni JG. Dental applications of advanced lasers (DAAL). JGM Associates; 2007.

[23]. Coluzzi DJ, Parker SP, editors. Lasers in dentistry-current concepts. Springer; 2017 Sep 21

[24]. Lomke MA. Clinical applications of dental lasers. Gen Dent. 2009 Feb;57(1):47-59.

[25]. Walsh LJ. The current status of laser applications in dentistry. Aust Dent J. 2003 Sep;48(3):146-55.

[26]. Dederich DN, Bushick RD; ADA Council on Scientific Affairs and Division of Science; Journal of the American Dental Association. Lasers in dentistry: separating science from hype. J Am Dent Assoc. 2004 Feb;135(2):204-12; quiz 229.Pubmed PMID: 15005437.

[27]. Dang, M, Ram, S. Integrating Laser Dentistry into Esthetic Dentistry. Int J Laser Dent 2012; 2: 63-68.

[28]. Kravitz ND, Kusnoto B. Soft-tissue lasers in orthodontics: an overview. Am J Orthod Dentofacial Orthop. 2008 Apr;133(4 Suppl):S110-4.Pubmed PMID: 18407017.

[29]. Kotlow L. Lasers and soft tissue treatments for the pediatric dental patient. Alpha Omegan. 2008 Sep 1;101(3):140-51. https://scholar.google.com/ scholar?hl=en\&as_sdt=0\%2C $5 \&$ q $=$ Lasers+and +soft+tissue+treatments+for +the+pediatric+dental+patient $\&$ btnG $=$

[30]. Sarver DM, Yanosky M. Principles of cosmetic dentistry in orthodontics: part 2. Soft tissue laser technology and cosmetic gingival contouring. Am J Orthod Dentofacial Orthop. 2005 Jan;127(1):85-90.Pubmed PMID: 15643420.

[31]. Ana PA, Blay A, Miyakawa W, Zezell DM. Thermal analysis of teeth irradiated with Er, Cr: YSGG at low fluences. Laser Phys. Lett. 2007 Jun $14 ; 4(11): 827-834$.

[32]. Gutknecht N, Van Betteray C, Ozturan S, Vanweersch L, Franzen R. Laser supported reduction of specific microorganisms in the periodontal pocket with the aid of an Er, Cr: YSGG laser: a pilot study. Sci. World J. 2015 Jan $1 ; 2015: 450258$.

[33]. Lee MT, Bird PS, Walsh LJ. Photo-activated disinfection of the root canal: a new role for lasers in endodontics. Aust Endod J. 2004 Dec;30(3):93-8.

[34]. Longo JP, Leal SC, Simioni AR, Almeida-Santos MD, Tedesco AC, Azevedo RB. Photodynamic therapy disinfection of carious tissue mediated by aluminum-chloride-phthalocyanine entrapped in cationic liposomes: an in vitro and clinical study. Lasers Med Sci. 2012 May 1;27(3):575-84.

[35]. Dörtbudak O, Haas R, Bernhart T, Mailath-Pokorny G. Lethal photosensitization for decontamination of implant surfaces in the treatment of periimplantitis. Clin Oral Implants Res. 2001 Apr;12(2):104-8.Pubmed PMID: 11251658.

[36]. Sarkar S, Wilson M. Lethal photosensitization of bacteria in subgingival plaque from patients with chronic periodontitis. J Periodontal Res. 1993 May;28(3):204-10.Pubmed PMID: 8388448.

[37]. Burns T, Wilson M, Pearson GJ. Effect of dentine and collagen on the lethal photosensitization of Streptococcus mutans. Caries Res. 1995;29(3):192-7. Pubmed PMID: 7621494.

[38]. Soukos NS, Wilson M, Burns T, Speight PM. Photodynamic effects of toluidine blue on human oral keratinocytes and fibroblasts and Streptococcus sanguis evaluated in vitro. Lasers Surg Med. 1996;18(3):253-9.Pubmed PMID: 8778520 .

[39]. Walsh LJ. Safety issues relating to the use of hydrogen peroxide in dentistry. Aust Dent J. 2000 Dec;45(4):257-69; quiz 289.Pubmed PMID: 11225528.

[40]. Coluzzi DJ. Fundamentals of dental lasers: science and instruments. Dent Clin North Am. 2004 Oct;48(4):751-70.Pubmed PMID: 15464551.

[41]. El-Housseiny AA, Jamjoum H. Evaluation of visual, explorer, and a laser device for detection of early occlusal caries. J Clin Pediatr Dent. 2001 Fall;26(1):41-8.Pubmed PMID: 11688812.

[42]. Lane PM, Gilhuly T, Whitehead P, Zeng H, Poh CF, Ng S, et al. Simple device for the direct visualization of oral-cavity tissue fluorescence. J Biomed Opt. 2006 Mar-Apr;11(2):024006.Pubmed PMID: 16674196.

[43]. Amorim Dos Santos J, Normando AGC, de Toledo IP, Melo G, De Luca Canto G, Santos-Silva AR, et al. Laser therapy for recurrent aphthous stomatitis: an overview. Clin Oral Investig. 2020 Jan;24(1):37-45.Pubmed PMID: 31720851.

[44]. Mukhtar R, Fazal MU, Saleem M, Saleem S. Role of low-level laser therapy in post-herpetic neuralgia: a pilot study. Lasers Med Sci. 2020 Oct;35(8):17591764.Pubmed PMID: 32006261.

[45]. Ross G, Ross A. Low level lasers in dentistry. Gen Dent. 2008;56(7):629- 
634

[46]. Isola G, Matarese M, Briguglio F, Grassia V, Picciolo G, Fiorillo L, et al. Effectiveness of low-level laser therapy during tooth movement: A randomized clinical trial. Materials. 2019 Jan;12(13):2187.

[47]. Biagi R, Cossellu G, Sarcina M, Pizzamiglio IT, Farronato G. Laser-assisted treatment of dentinal hypersensitivity: a literature review. Ann Stomatol (Roma). 2016 Feb 12;6(3-4):75-80.Pubmed PMID: 26941892.

[48]. Landucci A, Wosny AC, Uetanabaro LC, Moro A, Araujo MR. Efficacy of a single dose of low-level laser therapy in reducing pain, swelling, and trismus following third molar extraction surgery. Int J Oral Maxillofac Surg. 2016 Mar;45(3):392-8.Pubmed PMID: 26691932.

[49]. Knapp DJ. Postherpetic neuralgia: case study of class 4 laser therapy intervention. Clin J Pain. 2013 Oct;29(10):e6-9.Pubmed PMID: 24384987.

[50]. Falaki F, Nejat AH, Dalirsani Z. The effect of low-level laser therapy on trigeminal neuralgia: a review of literature. J Dent Res Dent Clin Dent Prospects. 2014;8(1):1-5.

[51]. Dougherty TJ. An update on photodynamic therapy applications. J Clin Laser Med Surg. 2002 Feb 1;20(1):3-7.

[52]. Anzengruber F, Avci P, de Freitas LF, Hamblin MR. T-cell mediated anti-tumor immunity after photodynamic therapy: why does it not always work and how can we improve it? Photochem Photobiol Sci. 2015 Aug;14(8):14921509.Pubmed PMID: 26062987.

[53]. Oleinick NL, Morris RL, Belichenko I. The role of apoptosis in response to photodynamic therapy: what, where, why, and how. Photochem Photobiol Sci. 2002 Jan;1(1):1-21. Pubmed PMID: 12659143.

[54]. Han Y, Xu S, Jin J, Wang X, Liu X, Hua H, et al. Primary Clinical Evaluation of Photodynamic Therapy With Oral Leukoplakia in Chinese Patients. Front Physiol. 2018 Jan 22;9:01911.Pubmed PMID: 30723421.

[55]. Cosgarea R, Pollmann R, Sharif J, Schmidt T, Stein R, Bodea A, et al. Photodynamic therapy in oral lichen planus: A prospective case-controlled pilot study. Sci Rep. 2020 Feb 3;10(1):1667.Pubmed PMID: 32015380.

[56]. Konopka KR, Goslinski TO. Photodynamic therapy in dentistry. J Dent Res. 2007 Aug;86(8):694-707.

[57]. Matos AB, de Azevedo CS, da Ana PA, Botta SB, Zezell DM. Laser technology for caries removal. Contemporary Approach to Dental Caries. 2012
Mar 14;1.

[58]. Japanese Society for Laser Dentistry. Safety guidelines for the laser removal of dental calculus. Laser Ther. 2012 Jul 3;21(2):137-45.Pubmed PMID: 24610992.

[59]. Moritz A, Gutknecht N, Doertbudak O, Goharkhay K, Schoop U, Schauer $\mathrm{P}$, et al. Bacterial reduction in periodontal pockets through irradiation with a diode laser: a pilot study. J Clin Laser Med Surg. 1997 Feb;15(1):33-7. Pubmed PMID: 9467340

[60]. Ishikawa I, Aoki A, Takasaki AA, Mizutani K, Sasaki KM, Izumi Y. Application of lasers in periodontics: true innovation or myth?. Periodontology 2000. 2009 Jun;50(1):90-126.

[61]. Romanos G. Current concepts in the use of lasers in periodontal and implant dentistry. J Indian Soc Periodontol. 2015 Sep-Oct;19(5):490-4.Pubmed PMID: 26644712.

[62]. Azma E, Safavi N. Diode laser application in soft tissue oral surgery. J Lasers Med Sci. 2013;4(4):206-211.

[63]. Elbay M, Tak Ö, Sermet Elbay Ü, Kaya C, Eryylmaz K. The use of low-level laser therapy for controlling the gag reflex in children during intraoral radiography. Lasers Med Sci. 2016 Feb;31(2):355-61.Pubmed PMID: 26754182.

[64]. Goel H, Mathur S, Sandhu M, Jhingan P, Sachdev V. Effect of Low-level LASER Therapy on P6 Acupoint to Control Gag Reflex in Children: A Clinical Trial. J Acupunct Meridian Stud. 2017 Oct;10(5):317-323.Pubmed PMID: 29078966.

[65]. Rochkind S, Drory V, Alon M, Nissan M, Ouaknine GE. Laser phototherapy $(780 \mathrm{~nm})$, a new modality in treatment of long-term incomplete peripheral nerve injury: a randomized double-blind placebo-controlled study. Photomed Laser Surg. 2007 Oct;25(5):436-42.Pubmed PMID: 17975958.

[66]. Ozen T, Orhan K, Gorur I, Ozturk A. Efficacy of low level laser therapy on neurosensory recovery after injury to the inferior alveolar nerve. Head Face Med. 2006 Feb 15;2:3.Pubmed PMID: 16480503.

[67]. Diker N, Aytac D, Helvacioglu F, Oguz Y. Comparative effects of photobiomodulation therapy at wavelengths of 660 and $808 \mathrm{~nm}$ on regeneration of inferior alveolar nerve in rats following crush injury. Lasers Med Sci. 2020 Mar;35(2):413-420.Pubmed PMID: 31273571. 